\title{
The efficacy of adding vitamin B12 to pegylated interferon and ribavirin treatment in Hepatitis $C$ virus patients regarding the host and viral prognostic factors
}

\author{
Marjan Mokhtare ${ }^{1}$, Ahmad Darvishi Zeidabadi ${ }^{2}$, Mansour Bahardoust ${ }^{3}$, Saeid Safari ${ }^{4}$, Mitra Barati ${ }^{5}$, Shahram \\ Agah $^{1}$, Mahsa Motavaf ${ }^{6, *}$
}

${ }^{1}$ Colorectal Research Center, Iran University of Medical Sciences, Tehran, Iran

${ }^{2}$ Iran University of Medical Sciences, Tehran, Iran

${ }^{3}$ Colorectal Research Center, Epidemiology and Biostatics Department, Iran University of Medical Sciences Tehran, Iran

${ }^{4}$ Department of Anesthesiology, Rasoul Akram Medical Center, Iran University of Medical Sciences, Tehran, Iran

${ }^{5}$ Pediatrics Infectious Diseases Research Center, Iran University of Medical Sciences, Tehran, Iran

${ }^{6}$ Department of Molecular Genetics, Faculty of Biological Science, Tarbiat Modares University, Tehran, Iran

Correspondence

Mahsa Motavaf, Department of Molecular Genetics, Faculty of Biological Science, Tarbiat Modares University, Tehran, Iran

Email: motavaf.m@gmail.com

History

- Received: Nov 21, 2018

- Accepted: Feb 06, 2019

- Published: Feb 28, 2019

DOI :

https://doi.org/10.15419/bmrat.v6i2.524

\section{Check for updates}

\section{Copyright}

(c) Biomedpress. This is an openaccess article distributed under the terms of the Creative Commons Attribution 4.0 International license.

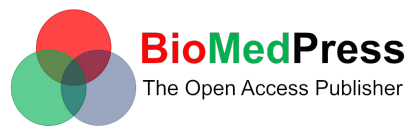

\begin{abstract}
Introduction: Hepatitis C virus (HCV) infection affects almost 180 million people around the world. Even though the development of direct acting antivirals (DAAs) has significantly improved the treatment responses to HCV infection, treatment with pegylated interferon (PeglFN) in combination with ribavirin is considered the standard of care (SOC) for chronic HCV infection treatment in countries with limited medical resources. Considering the inhibitory effect of vitamin B12 on HCV replication, we have evaluated the effect of vitamin B12 supplementation along with SOC on treatment outcomes in patients with chronic HCV infection, who were antiviral treatment-naive. Methods: In this regard, seventy-four HCV-infected patients, naïve to antiviral therapy, were randomly assigned to receive $\mathrm{SOC}$ or SOC in addition to vitamin B12 (SOC + B12). Viral response was evaluated at 4 , 12,24 and 48 weeks following the initiation of viral treatment and at 24 weeks after completing the treatment. Genotyping of the interleukin 28B (IL28B) polymorphisms was also performed. Demographic characteristics, clinical findings, fibroscan results and drug adverse effects were recorded. Results: Our findings showed that rapid viral response was not significantly different between the two groups; however, the rates of complete early viral response (cEVR) $(p=0.033)$, end-of-treatment viral response (ETVR) $(p=0.001)$ and sustained virologic response (SVR) $(p=0.0001)$ were significantly higher in SOC + B12 patients compared to SOC patients. Besides, in SOC + B12 patients, those with a higher baseline viral load and carriers of IL28B CC genotype showed significantly higher rate of SVR. Conclusion: In conclusion, the addition of vitamin B12 significantly improved the rate of SVR in HCV-infected patients, who were naïve to antiviral therapy. As this treatment regimen is safe and inexpensive, it proposes an option for improving the effectiveness of the HCV treatment with SOC, particularly in resource-limited settings.

Key words: Hepatitis C virus, Pegylated Interferon, Ribavirin, Vitamin B12
\end{abstract}

\section{INTRODUCTION}

Hepatitis C virus (HCV) is a leading cause of liverrelated mortalities and morbidities and is a major health concern worldwide. With the emergence of approximately 3-4 million new cases of HCV infection every year, it is estimated that $2 \%-3 \%$ (130-170 million) of the world population are chronically infected ${ }^{1}$. HCV transmission occurs principally via the exposure to contaminated blood or blood products. The most important mode of HCV transmission is needle sharing among intravenous (IV) drug users. Blood transfusion, tattooing, and sexual contacts are possible ways of spreading $\mathrm{HCV}$ infection ${ }^{2}$. Although the infection is preliminary acute, about $75 \%-85 \%$ of infected patients fail to clear the virus within 6 months and gradually progress to chronic infection ${ }^{3}$. Among chronically infected cases, $10 \%-20 \%$ of patients develop liver cirrhosis over a period of 20-30 years, and of those with cirrhosis, $1 \%-5 \%$ will develop hepatocellular carcinoma (HCC) annually. As a result, on a global scale, chronic HCV infection is responsible for approximately 250000 to 350000 deaths annually, which are mostly related to the decompensation of cirrhosis, end-stage liver disease, and $\mathrm{HCC}^{4-6}$.

Diagnostic tests for HCV infection use serological assays to detect specific antibodies to HCV (anti$\mathrm{HCV}$ ) and molecular techniques to detect HCV-RNA in blood serum or plasma. A positive HCV antibody immunoassay test reveals an exposure to HCV; however, as patients who have spontaneously cleared the disease may produce false-positive anti-HCV results, it should be followed with a qualitative or quantitative polymerase chain reaction (PCR) test to detect the presence of HCV RNA in the blood ${ }^{7,8}$.

Based on sequence homology analysis, at least seven major HCV genotypes and numerous distinct sub-

Cite this article : Mokhtare M, Zeidabadi A D, Bahardoust M, Safari S, Barati M, Agah S, Motavaf M. The efficacy of adding vitamin B12 to pegylated interferon and ribavirin treatment in Hepatitis $C$ virus patients regarding the host and viral prognostic factors . Biomed. Res. Ther.; 6(2):3016- 3026. 
types have been determined. Due to the genetic heterogeneity of HCV, evolution or existence of different $\mathrm{HCV}$ quasispecies in each patient, and the low efficient in vitro virus propagation, the development of $\mathrm{HCV}$ vaccine remains challenging.

The proximate goal of HCV treatment is viral eradication, which is achieved by eliminating detectable circulating HCV 6 months after treatment cessation. Between 2001 and 2011, standard treatment for chronic $\mathrm{HCV}$ infection was based on the use of PegIFN $\alpha$ $2 \mathrm{a}$ or $2 \mathrm{~b}$ in combination with ribavirin, known as SOC. This treatment regimen yields an SVR in 40$80 \%$ of cases depending on different viral and host parameters $^{9,10}$. The recently developed DAAs are consisting of protease inhibitors, NS5A inhibitors, nucleotide analog NS5B polymerase inhibitor and the non-nucleotide polymerase inhibitor ${ }^{7,11-13}$. These new treatments improve SVR rates significantly in difficult cases such as genotype $1 \mathrm{HCV}$ infection ${ }^{13}$. Despite these advantages, in most of low- and middle income countries including Iran, access to these drugs is limited, mostly due to their high cost and unavailability ${ }^{14}$. Population based epidemiological studies have estimated that the prevalence of HCV in the Iranian general population is less than $0.5 \%$, which is relatively low ${ }^{15}$. Among the infected patients with genotype $1 \mathrm{a}, 3 \mathrm{a}$ and $1 \mathrm{~b}$ genotypes are known to be the most common genotypes ${ }^{16-18}$. Available studies have showed that several host factors including host genotypes (race, age, gender, IL28B), degrees of hepatic fibrosis prior to treatment response and virological genotypes and RNA levels can be used to predict SVR rates.

$\mathrm{HCV}$ is an enveloped RNA virus belonging to the family Flaviviridae ${ }^{19}$. The virus possesses an internal ribosomal entry site (IRES) at the $5^{\prime}$ untranslated region (UTR). The IRES is essential for the translation of viral polyprotein precursors. It is a complex RNA structure responsible for the correct assembling of ribosomal subunits at the viral start codons, which act through a mechanism that bypasses the canonical eukaryotic mRNA translation initiation. The unique structure and high sequence conservation of the $5^{\prime}$ UTR rendering IRES RNA represents a unique structure for drug targets.

Cobalamins, the class of compounds to which vitamin B12 belongs, are mostly stored in the human liver ${ }^{20}$. Recent studies have reported that various liver diseases such as acute hepatitis, cirrhosis, HCC, and metastatic liver diseases are associated with major alterations in plasma vitamin B12 concentrations ${ }^{21-23}$. Moreover, the results from an available in-vitro study have reported that vitamin B12 plays a natural role in the negative regulation of the HCV replication cy$\mathrm{cle}^{24}$. Based on these evidences, the possible role of vitamin B12 supplementation in improving the rates of viral response to antiviral therapy in $\mathrm{HCV}$ carriers has been investigated. Recently, vitamin B12 supplementation in HCV carriers showed a significant improvement in response to treatment with PegIFN and ribavirin at all time-points during therapy ${ }^{25}$. However, this study was conducted on a limited number of patients and no clinical study has investigated the implication of adding B12 to SOC in the setting of $\mathrm{HCV}$ treatments. The aim of this randomized clinical trial was to assess the effect of vitamin B12 addition to SOC on the viral response to antiviral therapy in patients with naïve chronic $\mathrm{HCV}$ infection.

\section{METHODS}

\section{Subjects}

Patients with chronic $\mathrm{HCV}$ infection and naïve to antiviral therapy were enrolled among those referred to the hepatology clinic of Rasoul-e-Akram university Hospital between 2014 and 2016. Patients either aged $<18$ or $>65$ years, with the history of treatment course with interferon and/or ribavirin, having conditions with consequences for liver disease, such as alcoholic liver disease, HBV or HIV infection, autoimmune hepatitis, HCC, decompensated cirrhosis, as well as severe synchronous disease or contraindications to treatment (depression, psychosis, epilepsy, uncontrolled hypertension, cytopenia (haemoglobin $<12 \mathrm{~g}$ $/ \mathrm{dL}$, leukocyte count $<3000 / \mathrm{mm}^{3}$, platelet count $<100000 / \mathrm{mm}^{3}$ ), or having severe cardiac and pulmonary disease were excluded from the study. Written consent to participate in the study was obtained from all patients. The study protocol was approved by the ethic committee of the Iran University of Medical Sciences (ethic code: Approval date; 2015-0415, 1394/01/26-Ethics committee No; 25592) and registered by the Iranian Registry Clinical Trial (IRCT Code: IRCT Id IRCT2015041720178N3).

\section{Study assessments}

After recording the baseline demographic data (Table 1), the following tests were performed for all patients: aspartate aminotransferase, alanine aminotransferase, alkaline phosphatase, complete blood cell count, total and direct bilirubin, albumin, prothrombin activity, C-reactive protein, thyroid functional test, fasting blood sugar, triglyceride, ferritin and cholesterol levels. Anti-HCV antibodies were detected by third generation enzyme-linked immunosorbent assay (Ortho. HCV Elisa Test System, Ortho Diagnostics), according to manufacture 


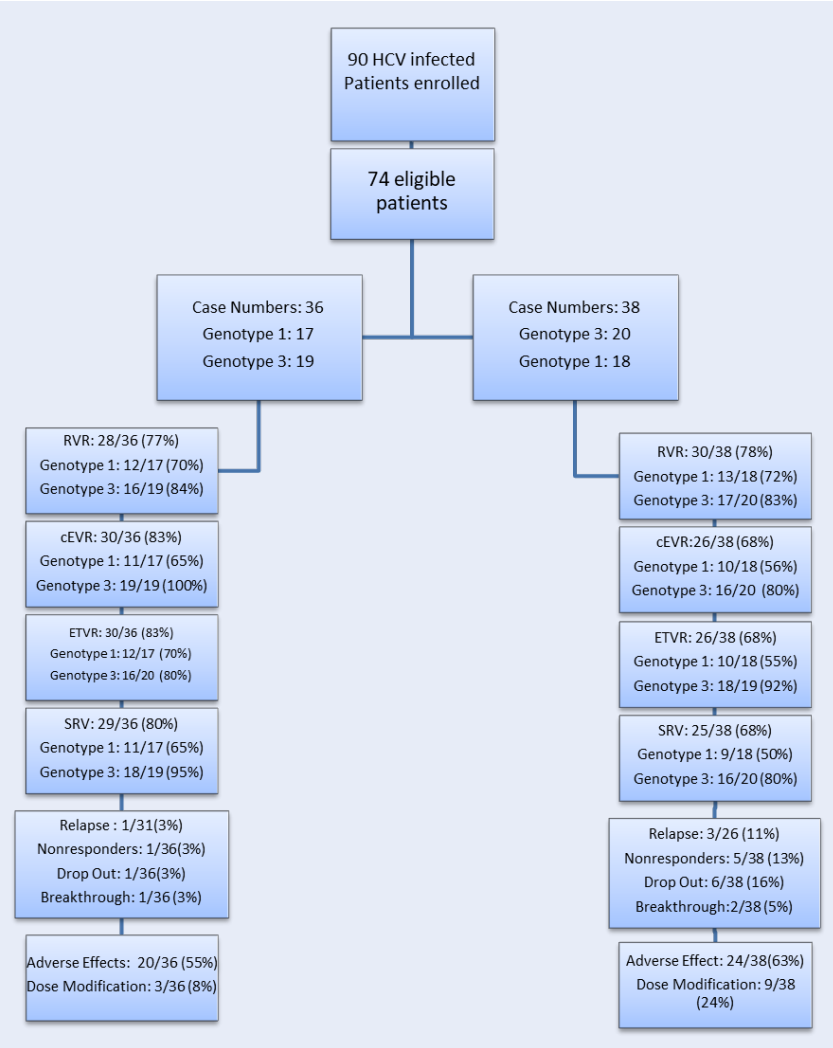

Figure 1: Flow of patients according to treatment arm and HCV genotype.

instruction. The presence of HCV-RNA in serum was determined by nested reverse transcription PCR (ROCHE; Roche Diagnostics GmbH, Roche Ap-plied Science, Mannheim, Germany). HCV genotype was identified by line-probe assay (INNO-LiPA ${ }^{T M}$ HCV II, Belgium, Innogenetics) test. Evaluation of liver stiffness was measured by fibroscan in all cases using Fibroscan FS502 touch and CAP system (Manufacturer; Echosense, France). The levels of steatosis were graded as follows: 0 (absent), 1 (30\% of hepatocytes affected), 2 (30-70\% of hepatocytes affected) and 3 ( $>70 \%$ of hepatocytes affected).

The rs $12979860 \mathrm{C} / \mathrm{T}$ polymorphism, located $3 \mathrm{~kb}$ upstream of the IL28b gene is known to have a powerful association in response to the treatment in $\mathrm{HCV}$, where $\mathrm{C}$ allele is the favorable allele for predicting $\mathrm{SVR}^{26}$. In this regard, we also performed genotyping of this polymorphism by PCR-based restriction fragment length polymorphism assay.

\section{Subjects Randomization and Treatment Regimen}

The participants were randomly assigned to one of the following treatment groups: PegIFN plus ribavirin and vitamin B12 (A group) or PegIFN plus ribavirin (B group). Randomization was carried out prior to the start of the trial using a computer-generated list prepared by a researcher not involved in the therapeutic regimes of patients, and unaware of patient characteristics except for the HCV genotype. PegIFN $\alpha 2 b$ (PegInteron,Shering -plough, Newjersy, USA) was used at a dosage of $1.5 \mathrm{mg} / \mathrm{kg} /$ week for all patients. In patients infected with HCV genotype 1 , ribavirin (Rebetol 200 mg hard capsule, Shering -plough, Newjersy, USA) was administered with a dosing based on body weight (1000 $\mathrm{mg}$ /day for patients weighing $<75$ $\mathrm{kg}, 1200 \mathrm{mg} /$ day for patients weighing $>75 \mathrm{~kg}$ ); in the case of infection by genotype 2 or 3 , a single ribavirin dose of $800 \mathrm{mg} /$ day was administered. The treatment continued for 24 and 48 weeks for genotypes 3 and 1 , respectively. Patients in the SOC+ B12 group received vitamin $\mathrm{B} 12$ at a dose of 5000 microgram by intramuscular injection every 4 weeks during the antiviral therapy.

\section{Treatment Efficacy Assessments}

The efficacy of treatment regimens was compared by viral response between two study groups. RVR was 
Table 1: Baseline demographic, imaging and laboratory data in both treatment groups

\begin{tabular}{|c|c|c|c|}
\hline & SOC + Vit B12 & SOC & P-value \\
\hline Age (mean \pm SD) & $44 \pm 12$ & $41 \pm 10$ & NS \\
\hline Sex (Male) n (\%) & $32(88 \%)$ & $33(85 \%)$ & NS \\
\hline \multicolumn{4}{|l|}{ HCV-Genotype n (\%) } \\
\hline $1 \mathrm{a}$ & $19(52 \%)$ & $20(52 \%)$ & NS \\
\hline 1a & $15(41 \%)$ & $16(42 \%)$ & NS \\
\hline $1 \mathrm{a} / \mathrm{b}$ & $1(2 \%)$ & $1(2 \%)$ & NS \\
\hline $1 \mathrm{a} / 3 \mathrm{a}$ & $1(2 \%)$ & $1(2 \%)$ & NS \\
\hline \multicolumn{4}{|l|}{ Baseline-HCV load n (\%) } \\
\hline$>600000 \mathrm{U} / \mathrm{L}$ & $9(25 \%)$ & $10(29 \%)$ & NS \\
\hline$<600000 \mathrm{U} / \mathrm{L}$ & $27(75 \%)$ & $28(71 \%)$ & NS \\
\hline \multicolumn{4}{|c|}{ Fibroscan; Steatosis score n (\%) } \\
\hline 0 & $14(38 \%)$ & $10(26 \%)$ & NS \\
\hline 1 & $8(22 \%)$ & $15(39 \%)$ & NS \\
\hline 2 & $4(11 \%)$ & $5(13 \%)$ & NS \\
\hline 3 & $10(27 \%)$ & $8(21 \%)$ & NS \\
\hline \multicolumn{4}{|c|}{ Fibrooscan; Fibrosis score n (\%) } \\
\hline 0 & $12(33 \%)$ & $15(39 \%)$ & NS \\
\hline 1 & $10(27 \%)$ & $9(23 \%)$ & NS \\
\hline 2 & $9(25 \%)$ & $10(26 \%)$ & NS \\
\hline 3 & $2(5 \%)$ & $2(5 \%)$ & NS \\
\hline 4 & $3(8 \%)$ & $2(5 \%)$ & NS \\
\hline AST (Mean \pm SD) & $57 \pm 21$ & $61 \pm 25$ & NS \\
\hline $\operatorname{ALT}($ Mean $\pm \mathrm{SD})$ & $79 \pm 37$ & $76 \pm 35$ & NS \\
\hline $\mathrm{TG}(\mathrm{Mean} \pm \mathrm{SD})$ & $101 \pm 61$ & $113 \pm 51$ & NS \\
\hline FBS $($ Mean \pm SD) & $95 \pm 13$ & $92 \pm 17$ & NS \\
\hline Cholesterol (Mean $\pm \mathrm{SD})$ & $164 \pm 26$ & $176 \pm 33$ & NS \\
\hline Smoker n (\%) & $24(66 \%)$ & $25(66 \%)$ & NS \\
\hline Addiction (non-IV) n (\%) & $23(63 \%)$ & $20(53 \%)$ & NS \\
\hline Alcohol user n (\%) & $21(58 \%)$ & $23(60 \%)$ & NS \\
\hline $\mathrm{BMI}($ Mean $\pm \mathrm{SD})$ & $24 \pm 4.79$ & $24 \pm 3.90$ & NS \\
\hline Platelet $($ Mean \pm SD) & $193000 \pm 610000$ & $211000 \pm 24000$ & NS \\
\hline $\mathrm{Hb}($ Mean $\pm \mathrm{SD})$ & $14 \pm 0.60$ & $14 \pm 0.50$ & NS \\
\hline Ferritin (Mean \pm SD ) & $77 \pm 12$ & $81 \pm 14$ & NS \\
\hline CRP $($ Mean \pm SD $)$ & $7 \pm 2$ & $7 \pm 3$ & NS \\
\hline
\end{tabular}

PEG-INF= PEGYLATED INTERFERON,RIBA= RIBAVERIN, BMI=Body Mass Index, CRP=C Reactive Protein, FBS=Fasting BloodSugar, $\mathrm{TG}=$ Triglyceride, AST $=$ Aspartate aminotransferase, $\mathrm{ALT}=$ Alaninetransaminase, $\mathrm{F}=\mathrm{Fibrosis}, \mathrm{S}=\mathrm{Steatosis}$ 


\begin{tabular}{llll}
\hline \multicolumn{2}{l}{ Table 2: Distribution of IL28B genotype between case and control groups } & \\
\hline IL28B GENOTYPE & SOC & SOC + VITAMIN B12 & P-value \\
& N (\%) & N (\%) & \\
3a- IL28B CT & $10(26 \%)$ & $8(22 \%)$ & 0.89 \\
3a- IL28B CC & $10(26 \%)$ & $9(24 \%)$ & 0.75 \\
3a- IL28B TT & $2(5 \%)$ & $2(5 \%)$ & 0.99 \\
1a- IL28B CC & $6(15 \%)$ & $8(22 \%)$ & 0.77 \\
1a- IL28B CT & $5(13 \%)$ & $3(8 \%)$ & 0.52 \\
1a- IL28B TT & $3(7 \%)$ & $3(8 \%)$ & 0.9 \\
1a/b- IL28B CT & $1(2 \%)$ & $2(5 \%)$ & 0.1 \\
1a/b- IL28B TT & $1(2 \%)$ & $1(1 \%)$ & 0.98 \\
\hline
\end{tabular}

defined as a negative HCV RNA test at week 4 of treatment. Undetectable serum HCV-RNA at week 12 of treatment was defined as cEVR, whereas an ETVR was defined as undetectable HCV RNA at the end of the treatment. SVR was defined as undetectable serum HCV-RNA level at 24 weeks after cessation of antiviral therapy. The reappearance of HCV-RNA during treatment was defined as virological breakthrough. Patients who showed HCV-RNA rebound after achieving ETVR were considered as early 'relapse' and if it occurred after the achievement of SVR, they were defined as "late relapse'. Discontinuation of treatment due to adverse events was defined as dropout. Termination of treatment was assignable to patients who either did not obtain a declined serum HCV-RNA concentration at least 2 logs under baseline at week 12 or did not achieve clearance of serum HCV-RNA level after 24 weeks of treatment. Patients who assigned to treatment discontinuation were defined as 'non-responders'.

\section{Dose modifications}

The modifications of PEG-IFN and ribavirin doses during the course treatment were modified according to the AASLD guideline ${ }^{27}$. Briefly, if neutrophil count decreased to $\leq 750 / \mathrm{mm}^{3}$ or the platelet count decreased to $\leq 50,000 / \mathrm{mm}^{3}$, the dosage of PEG-IFN was reduced by half. Discontinuation of PEG-IFN treatment was mandatory if the neutrophil count increased to $\leq 500 / \mathrm{mm}^{3}$ or the platelet count reduced to $\leq 25,000 / \mathrm{mm}^{3}$.

If haemoglobin levels reduced to $\leq 10 \mathrm{~g} / \mathrm{dL}$ or if severe cough or intolerable itching occurred, the dosage of ribavirin was reduced to $200 \mathrm{mg}$ decrements. Ribavirin treatment was discontinued if a reduction of haemoglobin level to $\leq 8.5 \mathrm{~g} / \mathrm{dL}$ was observed.
Adherence to treatment was assessed based on patient self-reports during their monthly visit and at 12 week post-treatment according to the ' $80 / 80 / 80$ ' rule. Based on the percentage of PegIFN and ribavirin administered doses to the planned total dose and the percentage of duration of treatment to the planned duration, patients who received at least $80 \%$ of both medications for at least $80 \%$ of the total scheduled time were considered compliant.

\section{Follow-up}

The first 4 weeks (weekly) after treatment initiation and monthly physical examination, complete blood counts were performed for patients. Moreover, the levels of serum HCV-RNA and ALT were measured at $4,12,48$ and 72 weeks after antiviral therapy started. Autoimmune serologic markers and thyroid functional examinations were performed every 3 months. To minimize possible bias, laboratory findings were collected by staffs, who were unaware of the study hypothesis.

\section{Statistical analysis}

In this study, descriptive variables analysis was performed using a Chi-square test. Continuous variables were expressed as mean \pm SD. Normal distribution of the variables was evaluated by the Kolmogorov Smirnov test. Frequencies were calculated for categorical variables. The Mann-Whitney rank sum test and/or the Kruskal-Wallis test were used to compare two or more than two groups of continuous variables. To examine quantitative variables, $t$-test was used for comparison in two groups and ANOVA test was used to compare variables in more than two groups. In order to independently determine the effect of each baseline variables (gender, age, body mass index, score of fibrosis, the score of steatosis, the 
Table 3: Rates of rapid, early, end-of-treatment and sustained viral response in the two treatment groups

\begin{tabular}{|c|c|c|c|}
\hline & SOC & SOC + Vit B12 & P-value \\
\hline RVR & $30 / 38(78 \%)$ & $29 / 36(80 \%)$ & NS \\
\hline \multicolumn{4}{|l|}{ Genotype (n \%) } \\
\hline 1 & $13 / 18(72 \%)$ & $12 / 17(70 \%)$ & NS \\
\hline 3 & $17 / 20(85 \%)$ & $17 / 19(89 \%)$ & NS \\
\hline \multicolumn{4}{|c|}{ Baseline HCV Load } \\
\hline$>600000$ & 7/10(70\%) & 7/9(77\%) & NS \\
\hline$<600000$ & $23 / 28(82 \%)$ & $21 / 27(78 \%)$ & NS \\
\hline cEVR (n \%) & $26 / 38(68 \%)$ & $30 / 36(83 \%)$ & 0.033 \\
\hline \multicolumn{4}{|l|}{ Genotype } \\
\hline 1 & $10 / 18(56 \%)$ & $11 / 17(65 \%)$ & NS \\
\hline 3 & $16 / 20(80 \%)$ & $19 / 19(100 \%)$ & NS \\
\hline \multicolumn{4}{|c|}{ Baseline HCV Load } \\
\hline$>600000$ & $6 / 10(60 \%)$ & $6 / 9(67 \%)$ & 0.032 \\
\hline$<600000$ & $20 / 28(71 \%)$ & $25 / 27(92 \%)$ & \\
\hline ETVR & $26 / 38(68 \%)$ & $30 / 36(83 \%)$ & 0.001 \\
\hline \multicolumn{4}{|l|}{ Genotype } \\
\hline 1 & $10 / 18(55 \%)$ & $12 / 17(70 \%)$ & 0.001 \\
\hline 3 & $16 / 20(80 \%)$ & $18 / 19(92 \%)$ & 0.001 \\
\hline \multicolumn{4}{|c|}{ Baseline HCV Load } \\
\hline$>600000$ & $6 / 10(60 \%)$ & $6 / 9(67 \%)$ & 0.0001 \\
\hline$<600000$ & $20 / 28(80 \%)$ & $24 / 27(89 \%)$ & 0.0001 \\
\hline SVR & $25 / 38(68 \%)$ & $29 / 36(80 \%)$ & 0.0001 \\
\hline \multicolumn{4}{|l|}{ Genotype } \\
\hline 1 & $9 / 18(50 \%)$ & $11 / 17(65 \%)$ & 0.001 \\
\hline 3 & $16 / 20(80 \%)$ & 18/19(95\%) & 0.0001 \\
\hline \multicolumn{4}{|c|}{ Baseline HCV Load } \\
\hline$>600000$ & $5 / 10(50 \%)$ & $5 / 9(55 \%)$ & 0.001 \\
\hline$<600000$ & $20 / 28(71 \%)$ & $24 / 27(89 \%)$ & 0.001 \\
\hline \multicolumn{4}{|c|}{ Baseline Fibrosis (KPa) } \\
\hline$<9.6$ & $25 / 21(84 \%)$ & $24 / 29(83 \%)$ & NS \\
\hline$\geq 9.6$ & $4 / 25(16 \%)$ & $5 / 29(17 \%)$ & NS \\
\hline \multicolumn{4}{|c|}{ IL28B Genotyping } \\
\hline $\mathrm{CC}$ & $14 / 25(56 \%)$ & $17 / 29(58 \%)$ & NS \\
\hline TT & $4 / 25(16 \%)$ & $6 / 29(20 \%)$ & NS \\
\hline CT & $7 / 25(28 \%)$ & $6 / 29(20 \%)$ & NS \\
\hline Relapse & $3 / 26(11 \%)$ & $1 / 31(3 \%)$ & 0.044 \\
\hline Breakthough & $2 / 38(5 \%)$ & $1 / 36(3 \%)$ & \\
\hline Drop out & $6 / 38(16 \%)$ & $1 / 36(3 \%)$ & 0.001 \\
\hline Nonresponder & $5 / 38(13 \%)$ & $1 / 36(3 \%)$ & 0.001 \\
\hline
\end{tabular}


Table 4: Comparison of Clinical and Laboratory Adverse Effects between Case and Control Groups

\begin{tabular}{|c|c|c|c|}
\hline & $\begin{array}{l}\text { PegINF \& RIBA } \\
\mathrm{N}=\mathbf{3 8}\end{array}$ & $\begin{array}{l}\text { PegINF \& RIBA + Vit B12, } \\
\text { N=36 }\end{array}$ & P-value \\
\hline Discontinuation & $6 / 38(16 \%)$ & $1 / 36(3 \%)$ & 0.0001 \\
\hline Adverse effects (\%) & $24 / 38(63 \%)$ & $20 / 36(55 \%)$ & 0.0001 \\
\hline Dose modification & $9 / 38(24 \%)$ & $3 / 36(8 \%)$ & 0.0001 \\
\hline \multicolumn{4}{|l|}{ Laboratory abnormality } \\
\hline \multicolumn{4}{|l|}{ Anemia } \\
\hline $\mathrm{HB}<10$ & $6(16 \%)$ & $2(5 \%)$ & 0.001 \\
\hline $\mathrm{HB}<8.5$ & $1(2 \%)$ & 0 & 0.032 \\
\hline \multicolumn{4}{|l|}{ Neutropenia } \\
\hline$<750$ & $1(2 \%)$ & $1(2 \%)$ & NS \\
\hline$<500$ & 0 & 0 & NS \\
\hline \multicolumn{4}{|l|}{ Thrombocytopenia } \\
\hline$<50000$ & $1(2 \%)$ & 0 & NS \\
\hline$<25000$ & 0 & 0 & NS \\
\hline Fatigue & $15(39 \%)$ & $11(30 \%)$ & 0.0001 \\
\hline Headache & $12(31 \%)$ & $8(22 \%)$ & 0.001 \\
\hline Fever & $4(10 \%)$ & $1(2 \%)$ & 0.037 \\
\hline Flu-like & $9(23 \%)$ & $5(13 \%)$ & 0.0001 \\
\hline Arthralgia & $12(31 \%)$ & $9(25 \%)$ & NS \\
\hline Insomnia & $4(10 \%)$ & $3(8 \%)$ & NS \\
\hline Nausea & $4(10 \%)$ & $1(2 \%)$ & 0.0001 \\
\hline Alopecia Areata & $3(7 \%)$ & $2(5 \%)$ & NS \\
\hline Generalized Hair Loss & $13(34 \%)$ & $7(19 \%)$ & 0.0001 \\
\hline Irritability & $4(10 \%)$ & $2(5 \%)$ & NS \\
\hline Anorexia & $6(15 \%)$ & $6(16 \%)$ & NS \\
\hline Weight loss & $4(10 \%)$ & $1(2 \%)$ & 0.002 \\
\hline Depression & $13(34 \%)$ & $10(27 \%)$ & NS \\
\hline Diarrhea & $2(5 \%)$ & $1(2 \%)$ & NS \\
\hline Irregular Menstruation & $1(2 \%)$ & $1(2 \%)$ & NS \\
\hline Thyroid dysfunction & $1(2 \%)$ & 0 & NS \\
\hline
\end{tabular}


Table 5: Logistic regression analysis for host and viral factors that can predict the treatment outcomes in both treatment group

\begin{tabular}{lllllll}
\hline SVR (SCO +Vit B12) & & SE & P-value & Exp (B) & \multicolumn{2}{c}{ 95\%CI } \\
& & & & & Lower & Upper \\
Constant & -4.820 & 0.927 & 0.023 & 0.052 & - & - \\
IL28B-CC & 1.871 & 0.857 & $0.009^{*}$ & 3.12 & 1.87 & 9.53 \\
High Viral load & 0.054 & 0.376 & $0.049^{*}$ & 2.26 & 1.32 & 5.43 \\
\hline
\end{tabular}

Table 6: Multivariate analysis for all factors that predict SVR achievement in SOC treatment

\begin{tabular}{llllllc}
\hline SVR (SOC group) & & SE & P-value & Exp(B) & \multicolumn{2}{c}{ 95\%CI } \\
& & & & & Lower & Upper \\
Constant & -5.621 & 0.873 & 0.002 & 0.38 & - & - \\
IL28B-CC & 3.51 & 0.685 & $0.001^{*}$ & 2.87 & 1.42 & 8.72 \\
\hline
\end{tabular}

level of baseline HCV-RNA, HCV genotype, dose adjustment and treatment discontinuation), a univariate analysis was performed.

After the conventional data were interpreted, a logistic regression analysis was carried out to evaluate the impact of potential predictors for SVR by using SVRs (yes/no) as dependent variables and selected variables at baseline as independent factors. A comparative evaluation was performed to determine the effects of the various factors on the OR to obtain the SVR; thus, $Z$ scores were calculated for each factor and compared between groups. Statistical analysis of data was performed using the SPSS (PC V.22; SPSS Inc). The Pvalues of less than 0.05 were considered as statistically significant.

\section{RESULTS}

Of the 90 chronically infected patients that referred to our hepatology clinic, 16 were excluded from the study for the following reasons: having the history of treatment with interferon \pm ribavirin $(n=6)$, concomitant hepatitis B virus infection $(n=2)$, heavy alcohol consumption $(n=1)$, HCC $(n=1)$, severe depression $(n=3)$, poorly controlled diabetes $(n=1)$, and refused treatment $(n=2)$. Thus, 74 eligible patients were randomly assigned to receive one of these treatment regimens: PegIFN in combination with ribavirin (SOC (or PegIFN in combination with ribavirin plus vitamin B12 injections (SOC + Vit B12).

Patient's mean ages were respectively $44 \pm 12$ and $41 \pm 10$ years in SOC + Vit B12 and SOC grops. Majority of our patients were male in both groups. Dominant genotype of $\mathrm{HCV}$ was genotype 3 in both groups ( $A=19 / 36$ and $B=20 / 38$ ). The treatment groups did not show significant differences regarding to demographic, laboratory, virological and fibroscan parameters (Table 1). The distributions of IL28B genotypes were not significantly different between the two treatment groups (Table 2).

Viral response during antiviral therapy, at the end of treatment and during 24 weeks follow-up was reported in Table 3. Using ITT analysis, our results showed that the rates of cEVR (88\% vs. $68 \%$, $\mathrm{p}=0.033)$, ETVR ( $83 \%$ vs. $68 \%, \mathrm{p}=0.001)$ and SVR ( $80 \%$ vs. $68 \%, \mathrm{p}=0.0001)$ were significantly higher in group SOC + Vit B12 compared to group SOC. However, the rate of RVR in group SOC + Vit B12 and group SOC was not significantly different $(78 \%$ vs. $77 \%, \mathrm{p}=0.097)$. The relapse, drop out and nonresponder rates were significantly lower in group SOC + Vit B12 compared to group SOC. Viral breakthrough rate was not significantly different between two treatment groups (Table 3). Adverse events (especially in Fatigue, Headache, Fever, Flu-like, Nausea, Generalized Hair Loss, and Weight loss) were significantly lower in group SOC + Vit B12 compared to group SOC ( $55 \%$ vs. $63 \% \mathrm{P}=0.0001)$. The results of laboratory abnormality showed that, anemia was significantly lower in group treated with SOC + Vit B12 compared to group treated with SOC alone. Besides, necessitation of dose adjustment was significantly higher in group using SOC compared to group using SOC + Vit B12 (25\% vs. 8\%, $\mathrm{P}=0.0001)$. The dosage of PegIFN and/or ribavirin was respectively reduced in $9 / 38(24 \%)$ and $3 / 36(8 \%)$ patients in SOC and SOC + Vit B12 groups, mainly because of laboratory abnormalities (anaemia in SOC $=6$ and $\mathrm{A}=2$ cases, neutropenia in group SOC $+\mathrm{Vit} \mathrm{B} 12=1$ and $\mathrm{SOC}=1$ cases and thrombocytopenia in group $\mathrm{SOC}=$ 


\begin{tabular}{lcccccc}
\hline \multicolumn{2}{l}{ Table 7: Multivariate analysis for all factors that predict SVR achievement in SOC treatment } \\
\hline SVR & & SE & P-value & $\operatorname{Exp}(\mathbf{B})$ & \multicolumn{2}{c}{$\mathbf{9 5 \% C I}$} \\
& & & & & Lower & Upper \\
& & & & & - & - \\
Constant & -5.250 & 0.625 & 0.042 & 0.082 & 1.87 & 10.28 \\
Interleukin (cc) & 1.620 & 0.864 & 0.038 & 2.85 & 1.12 & 9.32 \\
Grope (vit b12) & 2.380 & 0.896 & 0.001 & 3.11 & &
\end{tabular}

1 case). Group SOC also showed significantly higher rate of treatment discontinuation compared to group SOC + Vit B12 (6/38 patients (16\%) vs. $1 / 36$ patients $(2 \%), \mathrm{P}=0.0001)$. Treatment discontinuation was caused by severe anemia ( 1 case), severe headache ( 2 cases), severe flu-like symptom (1 case), major depression and weight loss ( 1 case), thyroid function test abnormality ( 1 case) in group SOC and irritability and insomnia ( 1 case) in group SOC + Vit B12 (Table 4). When baseline parameters of HCV genotype (1 or 3), viral load, fibrosis score and IL28B genotype (CC, TT and $\mathrm{CT}$ ) were considered, the results of logistic regression analysis demonstrated that SVR rate was significantly higher in group SOC + Vit B12 patients who had higher viral count $(>600,000 \mathrm{IU} / \mathrm{ml})$ and IL28B CC genotype, and insignificantly higher in patients with HCV genotype 1 (Table 5).

Regarding multivariate analysis, adding vitamin B12 to treatment and genotype IL28B allele CC were considered as a prognostic factor to achieve SVR in this study (Tables 6 and 7).

Overall, the compliance with the $80 / 80 / 80$ rule was $>50 \%$ and group SOC + Vit B12 was significantly more adherent to treatment regimen than group SOC (30/36 (83\%) in group SOC + Vit B12 vs 26/38 (68\%) in group SOC). The flow of patients according to treatment arm and HCV genotype throughout the study is summarized in figure 1 (Figure 1).

\section{DISCUSSION}

For decades, PegIFN in combination with ribavirin was recommended as SOC for chronic hepatitis C virus infection ${ }^{28}$. The rate of SVR in patients receiving this treatment regimen is indicated to be $40-80 \%$, depending on various baseline parameters, such as HCV genotype, IL28B polymorphisms, gender and HCV RNA levels ${ }^{9}$. The introduction of DAAs has remarkably improved SVR rates in shorter duration of treatment, and with better tolerability in comparison to SOC. However, treatment with PegIFN in combination to RBV is still used in countries where DAAs are not available or are expensive. As only a fraction of patients with chronic hepatitis $\mathrm{C}$ infection would have access to such expensive therapies, optimizing efficacy of PegIFN and RBV combination therapy has become a research of interest over the past few years. For instance, available reports have showed that the addition of Sofosbuvir and vitamin D to the combination therapy with PegIFN plus Ribavirin can increase the rate of SVR among HCV-infected patients ${ }^{29-31}$.

Direct inhibitory effects of vitamin B12 on HCV IRES-dependent translation have been indicated by experimental evidences almost two decades ago ${ }^{24}$. Since then, several studies have reported the correlation between vitamin $\mathrm{B} 12$ and virological response of chronic hepatitis $\mathrm{C}$ infection receiving SOC ${ }^{25,32,33}$. Considering these evidences, the aim of the current study was to evaluate the possible effects of adding vitamin B12 by injection (at a dose of 5000 microgram) to PegIFN and RBV combination therapy on the virological response in treatment-naive patients with chronic HCV.

Here we provide evidence that addition of vitamin $\mathrm{B} 12$ to SOC significantly improves the rate of virological response in chronically $\mathrm{HCV}$ infected patients. Our findings showed that patients who received vitamin B12 during therapy achieved significantly higher rates of cEVR, ETVR and SVR compared to patients receiving PegIFN and RBV alone. Moreover, relapse, drop out and non-responder rates were significantly lower in this group. Patients who received PegIFN and RBV along with vitamin B12 experienced a significantly lower frequency of treatment side effects compared to those who received PegIFN and RBV only. Besides, necessitation of dose adjustment and treatment discontinuation was lower in patients who received vitamin B12 together with PegIFN and RBV. Our findings showed that SVR rate was significantly higher in patients receiving PegIFN and RBV plus vitamin B12, who had high viral count $>600,000 \mathrm{IU} / \mathrm{ml}$ and IL28B CC genotype. The association of $\mathrm{rs} 12979860(\mathrm{C} / \mathrm{T})$ polymorphism with both spontaneous and treatment-induced HCV clearance has been indicated in different studies ${ }^{34,35}$. Regarding multivariate analysis, our findings showed that adding vitamin B12 to treatment and genotype IL28B 
allele CC were prognostic factors to achieve SVR. The results of IL-28B genotyping in our patients did not show any significant differences in the distribution of IL-28B genotypes $(\mathrm{C} / \mathrm{C}, \mathrm{C} / \mathrm{T}$ and $\mathrm{T} / \mathrm{T})$ between two treatment groups, indicating that the higher rate of SVR observed in SOC + B12 patients was not affected by IL-28B genotype.

Our findings were in agreement with the open-label pilot study by Rocco et al. ${ }^{25}$, which reported that the addition of vitamin B12 to SOC significantly improved the rate of virological response in patients with chronic HCV infection. Accordingly, Rosenberg and Hagen $^{32}$, in their work showed that high levels of vitamin B12 in serum is favorable for achieving an ETVR in CHC patients treated with SOC. Contrary to these results, Mechie et al. ${ }^{21}$ reported that patients with lower baseline levels of serum vitamin B12 (cut-off value of $570 \mathrm{ng} / \mathrm{L}$ ) achieved higher rate of SVR compared to patients with vitamin B12 above the cut-off value. However, as the liver is the main physiological reservoir of human, and in hepatic diseases, the release of vitamin B12 is accrued due to hepatic necrosis. Thus, in these situations, the liver content of vitamin B12 was not necessarily correlated with the serum levels of vitamin B12.

\section{CONCLUSIONS}

In conclusion, our findings showed that the addition of vitamin B12 to SOC significantly improved the rates of treatment response in $\mathrm{HCV}$-infected patients. We are aware that the main limitations of our study were the small number of patients and lack of a placebo arm. Moreover, patients were not blinded to taking vitamin B12 and their baseline serum levels of vitamin B12 were not measured. Thus, the results should be interpreted cautiously. However, our findings along with previous research indicate that the addition of vitamin B12 improves the rate of virological response in chronic hepatitis $\mathrm{C}$ patients. As this treatment regimen is safe and inexpensive, it represents a promising option for improving the effectiveness of the HCV treatment with SOC, particularly in resource-limited settings.

\section{ABBREVIATIONS}

cEVR : Complete Early Viral Response

DDA : Direct Acting Antivirals

ETVR : End-of-Treatment Viral Response

HCV : Hepatitis C virus

IL28B : Interleukin 28B

IRES : Internal Ribosomal Entry Site

PegIFN : Pegylated Interferon
PCR : Polymerase Chain Reaction

RVR : Rapid Early Viral Response

SOC : Standard of Care

SVR : Sustain Early Viral Response

UTR : Untranslated Region

\section{COMPETING INTERESTS}

The authors declared no competing interests.

\section{AUTHORS' CONTRIBUTIONS}

Marjan Mokhtare, Ahmad Darvishi Zeidabadi, Mansour Bahardoust: developed the theory, carried out the experiment, performed the measurements, contributed to sample preparation.

Saeid Safari, Mitra Barati, Shahram, Agah, Mahsa Motavaf verified the analytical methods, contributed to the interpretation of the results, wrote the article. All authors read and approved the final manuscript.

\section{ACKNOWLEDGMENTS}

The authors would like to thank all participants for their contribution to the study.

\section{REFERENCES}

1. Hanafiah KM, Groeger J, Flaxman AD, Wiersma ST. Global epidemiology of hepatitis $C$ virus infection: new estimates of age-specific antibody to HCV seroprevalence. Hepatology. 2013;57(4):1333-42. 23172780. Available from: 10.1002/hep. 26141.

2. Alter MJ. Epidemiology of hepatitis $C$ virus infection. World J Gastroenterol. 2007;13(17):2436-41. 17552026. Available from: 10.3748/wjg.v13.i17.2436.

3. Kish T, Aziz A, Sorio M. Hepatitis C in a New Era: A Review of Current Therapies. P T. 2017;42(5):316-29. 28479841.

4. Chevaliez S, Pawlotsky JM. Hepatitis C virus: virology, diagnosis and management of antiviral therapy. World J Gastroenterol. 2007;13(17):2461-6. 17552030. Available from: 10.3748/wjg.v13.i17.2461.

5. Salim FB, Keyvani H, Amiri A, Sefidi FJ, Shakeri R, Zamani F. Distribution of different hepatitis $C$ virus genotypes in patients with hepatitis C virus infection. World J Gastroenterol. 2010;16(16):2005-9. 20419838. Available from: 10.3748/wjg. v16.i16.2005.

6. Westbrook RH, Dusheiko G. Natural history of hepatitis C. J Hepatol. 2014;61(1):S58-68. 25443346. Available from: 10. 1016/j.jhep.2014.07.012.

7. Shaheen MA, Idrees M. Evidence-based consensus on the diagnosis, prevention and management of hepatitis $C$ virus disease. World J Hepatol. 2015;7(3):616-27. 25848486. Available from: 10.4254/wjh.v7.i3.616.

8. Wilkins T, Malcolm JK, Raina D, Schade RR. Hepatitis C: diagnosis and treatment. Am Fam Physician. 2010;81(11):1351-7. 20521755.

9. Palumbo E. Pegylated interferon and ribavirin treatment for hepatitis C virus infection. Ther Adv Chronic Dis. 2011;2(1):3945. 23251740 . Available from: $10.1177 / 2040622310384308$.

10. Keshvari M, Alavian SM, Behnava B, Pouryasin A, Sharafi $\mathrm{H}$. The interferon lambda $4 \mathrm{rs} 368234815$ predicts treatment response to pegylated-interferon alpha and ribavirin in hemophilic patients with chronic hepatitis $C$. Journal of research in medical sciences : the official journal of Isfahan University of Medical Sciences. 2016;21:72. 
11. Keshvari M, Alavian SM, Behnava B, Pouryasin A, Craig JC, Sharafi H. Impact of IFNL4 rs12979860 and rs8099917 polymorphisms on response to Peg-Interferon- $\alpha$ and Ribavirin in patients with congenital bleeding disorder and chronic hepatitis C. J Clin Lab Anal. 2017;31(4):31. 27735085. Available from: 10.1002/jcla.22063.

12. Pawlotsky JM, Feld JJ, Zeuzem S, Hoofnagle JH. From nonA, non-B hepatitis to hepatitis C virus cure. J Hepatol. 2015;62(1):S87-99. 25920094. Available from: 10.1016/j.jhep. 2015.02.006

13. Barth $\mathrm{H}$. Hepatitis $\mathrm{C}$ virus: is it time to say goodbye yet? Perspectives and challenges for the next decade. World J Hepatol. 2015;7(5):725-37. 25914773. Available from: 10.4254/wih. v7.i5.725.

14. Ravi S, Toosi MN, Karimzadeh I, Ahadi-Barzoki M, Khalili H. Adherence to chronic hepatitis $C$ treatment regimen: first report from a referral center in iran. Hepat Mon. 2013;13(6):e11038. 24032043. Available from: 10.5812/hepatmon.11038.

15. Hajarizadeh B, Razavi-Shearer D, Merat S, Alavian SM, Malekzadeh R, Razavi H. Liver Disease Burden of Hepatitis $C$ Virus Infection in Iran and the Potential Impact of Various Treatment Strategies on the Disease Burden. Hepat Mon. 2016;16(7):e37234. 27642346. Available from: 10.5812/hepatmon.37234.

16. Khodabandehloo M, Roshani D. Prevalence of hepatitis C virus genotypes in Iranian patients: a systematic review and metaanalysis. Hepat Mon. 2014;14(12):e22915. 25685164. Available from: 10.5812/hepatmon.22915.

17. Samimi-Rad K, Nategh R, Malekzadeh R, Norder H, Magnius L. Molecular epidemiology of hepatitis $C$ virus in Iran as reflected by phylogenetic analysis of the NS5B region. J Med Virol. 2004;74(2):246-52. 15332273. Available from: 10.1002/ jmv. 20170.

18. Sefidi FJ, Keyvani H, Monavari SH, Alavian SM, Fakhim S, Bokharaei-Salim F. Distribution of hepatitis C virus genotypes in Iranian chronic infected patients. Hepat Mon. 2013;13(1):e7991. 23550108. Available from: 10.5812/ hepatmon.7991.

19. Rho J, Ryu JS, Hur W, Kim CW, Jang JW, Bae SH, et al. Hepatitis $\mathrm{C}$ virus (HCV) genotyping by annealing reverse transcriptionPCR products with genotype-specific capture probes. J Microbiol. 2008;46(1):81-7. 18337698. Available from: 10.1007/ s12275-007-0121-8.

20. Nicolas JP, Guéant JL. [Absorption, distribution and excretion of vitamin B12]. Ann Gastroenterol Hepatol (Paris). 1994;30(6):270-6. 7847789.

21. Mechie NC, Goralzcyk AD, Reinhardt L, Mihm S, Amanzada A. Association of serum vitamin B12 levels with stage of liver fibrosis and treatment outcome in patients with chronic hepatitis $C$ virus genotype 1 infection: a retrospective study. BMC Res Notes. 2015;8(1):260. 26109044. Available from: 10.1186/s13104-015-1248-z.

22. Koplay M, Gulcan E, Ozkan F. Association between serum vitamin B12 levels and the degree of steatosis in patients with nonalcoholic fatty liver disease. Journal of investigative medicine : the official publication of the American Federation for Clinical Research . 2011;59:1137-1140. Available from: 10.2310/JIM.0b013e31822a29f5.

23. Ermens AA, Vlasveld LT, Lindemans J. Significance of ele- vated cobalamin (vitamin B12) levels in blood. Clin Biochem. 2003;36(8):585-90. 14636871. Available from: 10.1016/j. clinbiochem.2003.08.004.

24. Lott WB, Takyar SS, Tuppen J, Crawford DH, Harrison M, Sloots TP, et al. Vitamin B12 and hepatitis C: molecular biology and human pathology. Proc Natl Acad Sci USA. 2001;98(9):491621. 11296247. Available from: $10.1073 /$ pnas. 081072798 .

25. Rocco A, Compare D, Coccoli P, Esposito C, Spirito AD, Barbato $A$, et al.. Vitamin B12 supplementation improves rates of sustained viral response in patients chronically infected with hepatitis $C$ virus; 2012.

26. Daneshvar $M$, Nikbin $M$, Talebi $S$, Javadi F, Aghasadeghi MR, Mahmazi S, et al. Role of IL28-B Polymorphism (rs12979860) on Sustained Virological Response to Pegylated Interferon/Ribavirin in Iranian Patients With Chronic Hepatitis C. Iran Red Crescent Med J. 2016;18(9):e28566. 28144454. Available from: 10.5812/ircmj.28566.

27. Ghany MG, Strader DB, Thomas DL, Seeff LB, for the Study of Liver Diseases American A. Diagnosis, management, and treatment of hepatitis C: an update. Hepatology. 2009;49(4):1335-74. 19330875. Available from: 10.1002/hep. 22759.

28. Tsubota A, Fujise K, Namiki Y, Tada N. Peginterferon and ribavirin treatment for hepatitis $C$ virus infection. World J Gastroenterol. 2011;17(4):419-32. 21274371. Available from: 10.3748/wjg.v17.i4.419.

29. Dolatimehr F, Karimi-Sari H, Rezaee-Zavareh MS, Alavian SM Behnava B, Gholami-Fesharaki M, et al. Combination of sofosbuvir, pegylated-interferon and ribavirin for treatment of hepatitis $C$ virus genotype 1 infection: a systematic review and meta-analysis. Daru. 2017;25(1):11. 28427463. Available from: 10.1186/s40199-017-0177-x

30. Vosoghinia H, Esmaeilzadeh A, Ganji A, Hosseini SM, Jamehdar SA, Salehi M, et al. Vitamin D in Standard HCV Regimen (PEG-Interferon Plus Ribavirin), Its Effect on the Early Virologic Response Rate: A Clinical Trial. Razavi International Journal of Medicine. 2016;4(2):e36632. Available from: 10 . 17795/rijm36632.

31. Nimer A, Mouch A. Vitamin D improves viral response in hepatitis $C$ genotype 2-3 naive patients. World J Gastroenterol. 2012;18(8):800-5. 22371640. Available from: 10.3748/wjg.v18. i8.800.

32. Rosenberg $\mathrm{P}$, Hagen $\mathrm{K}$. Serum $\mathrm{B} 12$ levels predict response to treatment with interferon and ribavirin in patients with chronic HCV infection. J Viral Hepat. 2011;18(2):129-34. 20196801. Available from: 10.1111/j.1365-2893.2010.01288.x.

33. Reda M. Impact of Serum Level of Vitamin B12 on Response to Combined Interferon and Ribavirin Therapy for Chronic HCV Infection. Med J Cairo Univ. 2016;84:529-35.

34. Melis R, Fauron C, McMillin G, Lyon E, Shirts B, Hubley LM et al. Simultaneous genotyping of rs 12979860 and rs 8099917 variants near the IL28B locus associated with HCV clearance and treatment response. J Mol Diagn. 2011;13(4):446-51. 21704279. Available from: 10.1016/j.jmoldx.2011.03.008.

35. Tipu I, Marriage F, Farooqi ZU, Platt H, Athar MA, Day PJ, et al. The IFN- $\lambda$ Genetic Polymorphism Association With the Viral Clearance Induced by Hepatitis C Virus Treatment in Pakistani Patients. Hepat Mon. 2014;14(3):e15076. 24734091. Available from: 10.5812/hepatmon.15076. 